\title{
Simultaneous Bilateral Facial Nerve Paralysis in a 4-Year-Old Child: A Rare Occurrence
}

Madhuri Mehta ${ }^{1}$ Vani Krishana Gupta ${ }^{1}$ Aniketh Pandurangi ${ }^{1} \quad$ Navroz Mehta ${ }^{1}$
Address for correspondence Madhuri Mehta, MBBS, MS ENT, Department of Ear, Nose, and Throat, NC Jindal Institute of Medical Sciences, Hisar, Haryana 125005, India (e-mail: drmadhurimehta@gmail.com).

\begin{abstract}
Keywords

- Bell's palsy

- facial nerve

- simultaneous paralysis

Paralysis of the facial nerve (cranial nerve VII) is a relatively uncommon entity in children. It not only results in weakness of the facial musculature affecting the facial expressions, eye closure, and oral competence, but also causes psychological and emotional trauma to the child and parents. Unilateral palsy is usually idiopathic, whereas bilateral palsy usually has an underlying cause. We report a case of a 4-year-old girl who presented to us with simultaneous facial nerve paralysis where the second side was involved within 7 days of the first, before its complete resolution. Evaluation of the patient and the possible etiologies of bilateral facial palsy have been discussed further.
\end{abstract}

\section{Introduction}

Facial nerve palsy is a serious clinical entity and even more worrisome if found in pediatric population. Although the incidence of facial palsy in children is two to four times lesser than in adults, its implications in the child, parents, and the treating physician are of greater concern. ${ }^{1}$ Bilateral facial nerve palsy is very rare and seen in less than $2 \%$ of all facial nerve palsy patients. This amounts to an incidence of 1 in 50,00,000 population, both pediatric and adult. ${ }^{2}$ The term simultaneous onset facial palsy is referred to when the involvement of the opposite side is within 30 days of onset of the first side. ${ }^{3}$ Unlike unilateral palsy, bilateral palsy is usually a manifestation of an underlying systemic disease, the diagnosis of which requires an extensive workup and is often left undiagnosed. Regardless of the cause, the loss of facial expressions is drastic and creates a panic in parents, making the physician's job of early diagnosis and treatment crucial.

\section{Case Report}

Parents of a 4-year-old girl presented to us with a complaint of complete loss of facial expressions since past 1 month. The symptom was insidious in onset and started with weakness of the right side of face 45 days ago. The parents noticed deviation of angle of mouth to the left side and incomplete eye closure on the right side. Weakness was noticed on the left side a week after the right-sided weakness. They noticed complete loss of facial expressions and consulted a pediatrician. The child was seen by us at the ENT Out Patient Department of our tertiary care hospital. There was no history of fever, cough, headache, ear discharge, or reduced hearing in the past. There were no complaints of reduced lacrimation or loss of taste sensation. She had no history of any trauma or surgery to the temporal area in the recent past. She had no history of skin lesions or contact with any stray animals.

On examination, the child had a dull, expression-less face. She was afebrile with stable vitals. She had bilateral incomplete eye closure even with maximal effort and no wrinkling of forehead muscles on looking up. She was unable to puff her cheeks with air or crinkle her nose. A bilateral grade-VI facial palsy (lower motor neuron) was diagnosed (House-Brackmann grading). ${ }^{4}$ Examination of other cranial nerves was normal. There was no motor weakness or sensory loss with no cerebellar signs. Ear, nose, and throat examination did not reveal any significant findings. Her pure tone audiogram was normal. We admitted her for further evaluation of the cause and treatment of facial palsy.

On investigating, we found a normal hemogram with a total leukocyte count of $7.400 / \mathrm{mm}^{3}$. Other tests, such as erythrocyte sedimentation rate (ESR) and blood sugar, were normal. Antinuclear antibodies (ANA) and cytoplasmic antineutrophil antibodies (c-ANCA), immunoglobulin (Ig)-M, EpsteinBarr virus (EBV) antibodies, and viral capsid antigen (VCA) were negative. Chest X-ray was normal. A high-resolution computed tomography (CT) scan of the temporal bone was done which showed no evidence of middle ear infections or 
facial nerve injury or compression ( - Figs. 1 and 2). Magnetic resonance imaging (MRI) brain showed a normal seventh and eighth nerve complex with no significant findings ( - Fig. 3 ). The child was treated with intravenous antibiotics and steroids along with acyclovir. Eye care for the protection of cornea was given. There was no progression of her symptoms during her 3 days of hospital stay. She was discharged with stable vitals and oral medications for a week.

On subsequent examination after 2 weeks, child came with a smiling face. Facial weakness had completely recovered on the left side (grade I) with mild weakness (grade II) on the right side. When examined 6 weeks later, she had completely recovered (grade I) on both the sides and has remained asymptomatic until date. - Fig. 4-6 and -Videos 1-3 show facial palsy at the time of presentation and 2 and 8 weeks after starting therapy, respectively.

\section{Discussion}

Facial palsy in children is a relatively uncommon condition and bilateral palsy is even rarer. Unlike unilateral palsy, where idiopathic cause is most common $(>50 \%)$, bilateral palsy is usually a manifestation of an ongoing systemic condition (idiopathic causes $<20 \%$ ). ${ }^{3}$ This makes the diagnosis of the underlying cause a challenge. Simultaneous facial palsy is seen in less than $1 \%$ cases of facial palsy. ${ }^{5}$ Out of this $1 \%$, pediatric cases are even fewer. Historically, bilateral facial palsy has been documented on rare occasions. Despite his extensive research in facial nerve and its palsy, Charles Bell deferred to a French report to quote an example of bilateral facial nerve palsy. ${ }^{6}$ William Hammond through his eight editions of American neurology textbook expressed his regret of

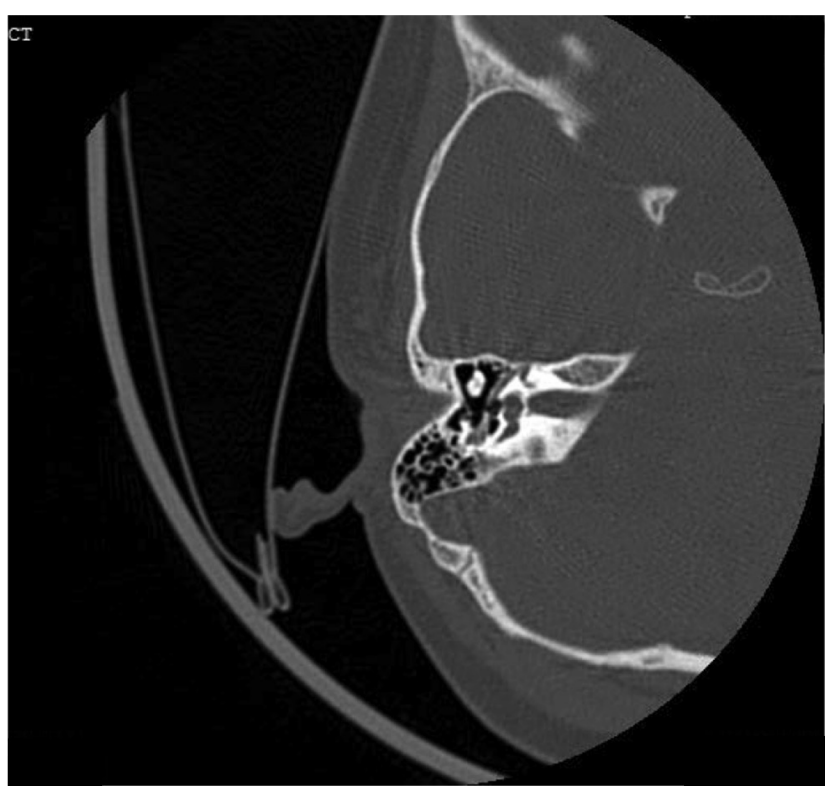

Fig. 1 HRCT temporal bone axial section of the right ear showing normal ossicles, clear middle ear space and normal first and second parts of the facial nerve. HRCT, high-resolution computed tomography.

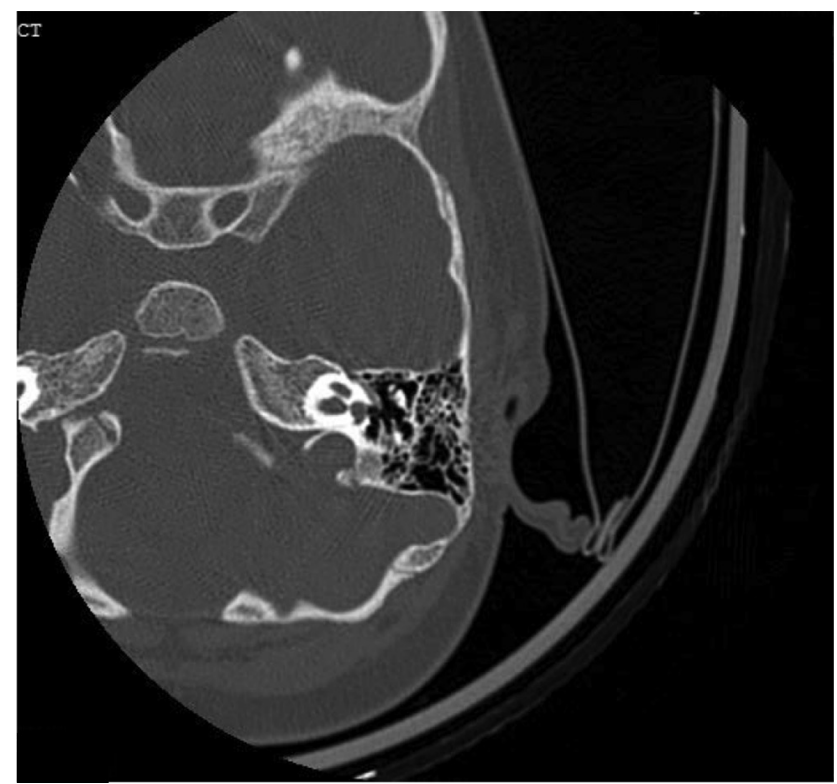

Fig. 2 HRCT temporal bone axial section of the left ear showing normal ossicles, clear middle ear space, and normal first and second parts of the facial nerve. HRCT, high-resolution computed tomography.

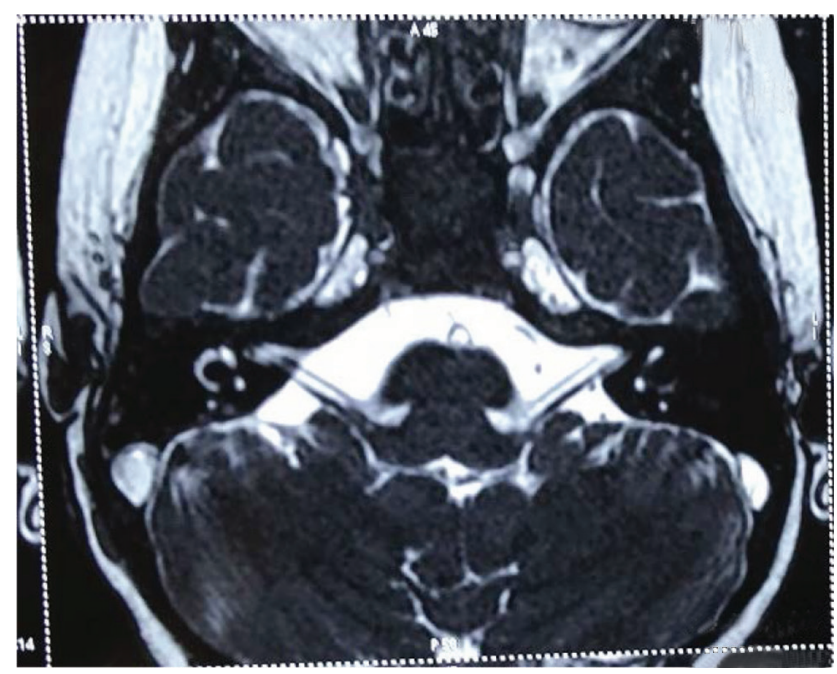

Fig. 3 MRI brain axial section showing a normal 7th-8th nerve complex on both the sides. MRI, magnetic resonance imaging.

not photographing the one bilateral facial palsy case that he had come across.

The list of possible etiology of bilateral facial palsy is numerous and it is helpful to categorize the possible causes into categories of infections, trauma, neurological, neoplasm, metabolic, autoimmune, or idiopathic. Some of these causes have been enumerated in $\boldsymbol{\sim}$ Table $1 .^{8}$ Teller and Murphy in their review of bilateral facial palsy cases over 10 years, reported few common causes of the same. Lyme disease consisted of $36 \%$ of the cases, followed by GuillainBarre syndrome (GBS; $5 \%)$, trauma (4\%), sarcoidosis (0.9\%), and $\operatorname{HIV}(0.9 \%){ }^{9}$

Lyme disease is not an endemic disease in India and rare in Haryana. ${ }^{10}$ It can cause unilateral or bilateral facial 
A

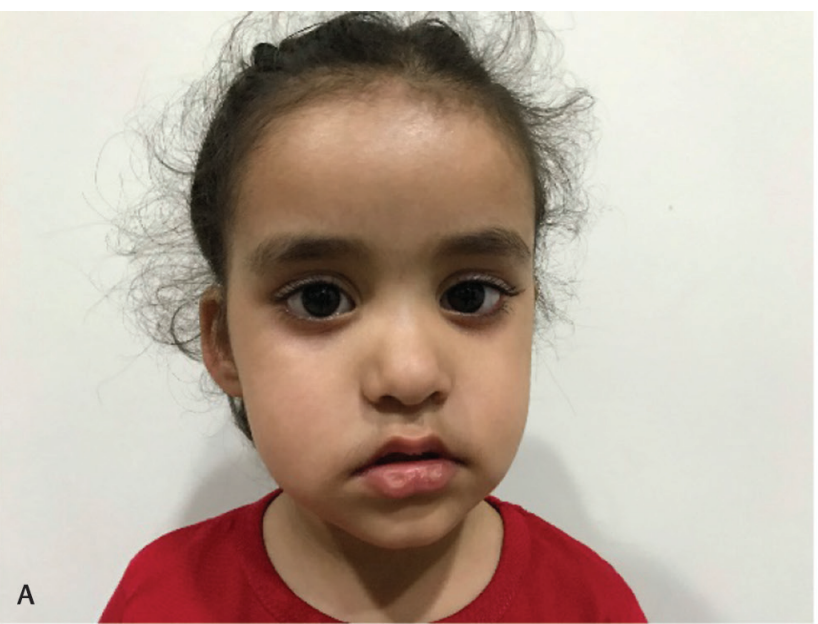

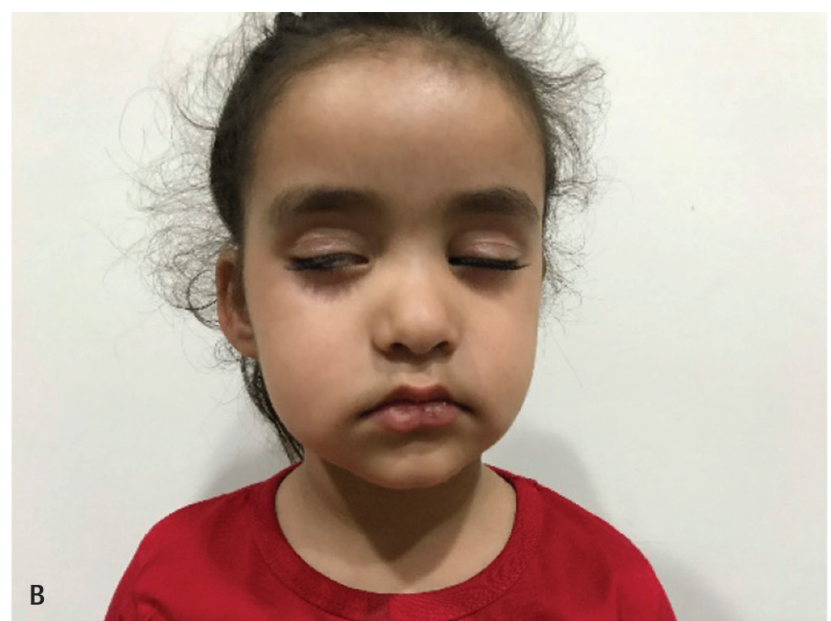

Fig. 4 (A) At first visit, bilateral grade VI palsy: inability to frown, blow air, show teeth, absence of nasolabial fold leading to expressionless face. (B) Incomplete eye closure (some amount of closure is present due to sympathetic over activity).
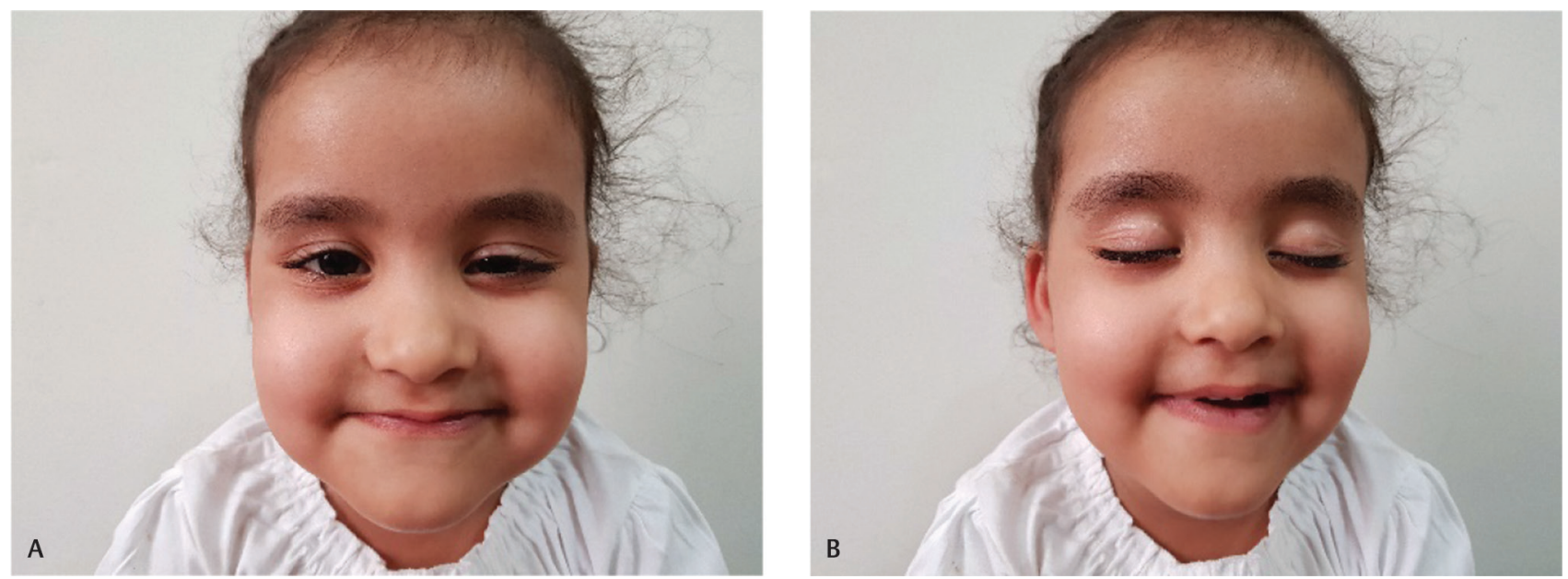

Fig. 5 (A) After 2 weeks of treatment, left side recovery seen with complete eye closure (grade I). (B) Right side, reduced movement on showing teeth (grade II).

paralysis which can last up to 2 months and is usually associated with other neurological defects. These children commonly present with painless facial swelling and erythema prior to facial palsy. ${ }^{11}$ In endemic areas, serological tests (IgM, IgG antibodies against Borrelia burgdoferi) are indicated to diagnose Lyme disease. In rapidly progressive facial palsy, cerebrospinal fluid analysis for these antibodies is useful.

Cases of GBS with bilateral facial palsy have been reported. In a case series by Kim et al, amongst 900 patients of GBS, only eight patients $(<1 \%)$ manifested with facial diplegia. ${ }^{12}$ Patients usually present with peripheral areflexia with a diagnostic lumbar puncture finding of elevated proteins in the absence of raised cell count.

In our patient, traumatic skull fractures and tumors of brain and temporal bone were excluded by normal CT and MRI imaging. Diabetes, HIV, and leukemia were excluded by normal blood tests. EBV infectious mononucleosis is usually subclinical. Facial palsy caused by this infection maybe bilateral (40\%). ${ }^{13}$ In our patient, the IgM antibodies against
EBV VCA were negative. Positive EBV serological tests have been associated with Bell's palsy as well. Sarcoidosis is an uncommon cause of facial diaplegia and was ruled out by a normal chest X-ray. Autoimmune causes were ruled out by the absence of other systemic symptoms, a negative c-ANCA, ANA, and normal ESR, and C-reactive protein.

Bell's palsy is self-limiting, spontaneously remitting and non-life-threatening. ${ }^{14}$ Analysis of 43 cases of bilateral facial palsy cases done by Keane published in 1944, showed that Bell's palsy was responsible for $23 \%$ of the cases, ${ }^{8}$ whereas in a series of 1,000 cases, Adour et al found only three bilateral palsy cases. ${ }^{4}$ Bell's palsy usually presents with a sudden unilateral facial paralysis without any other otological or central nervous system disease. It is thought to be caused by edema and ischemia resulting in compression of the labyrinthine segment of the facial nerve. The cause of edema and ischemia is still debated and herpes simplex virus (HSV) has been found to be the most likely cause. ${ }^{15}$

As our patient fit into these criteria and we excluded all other usual causes of bilateral facial palsy, we suspected her to 

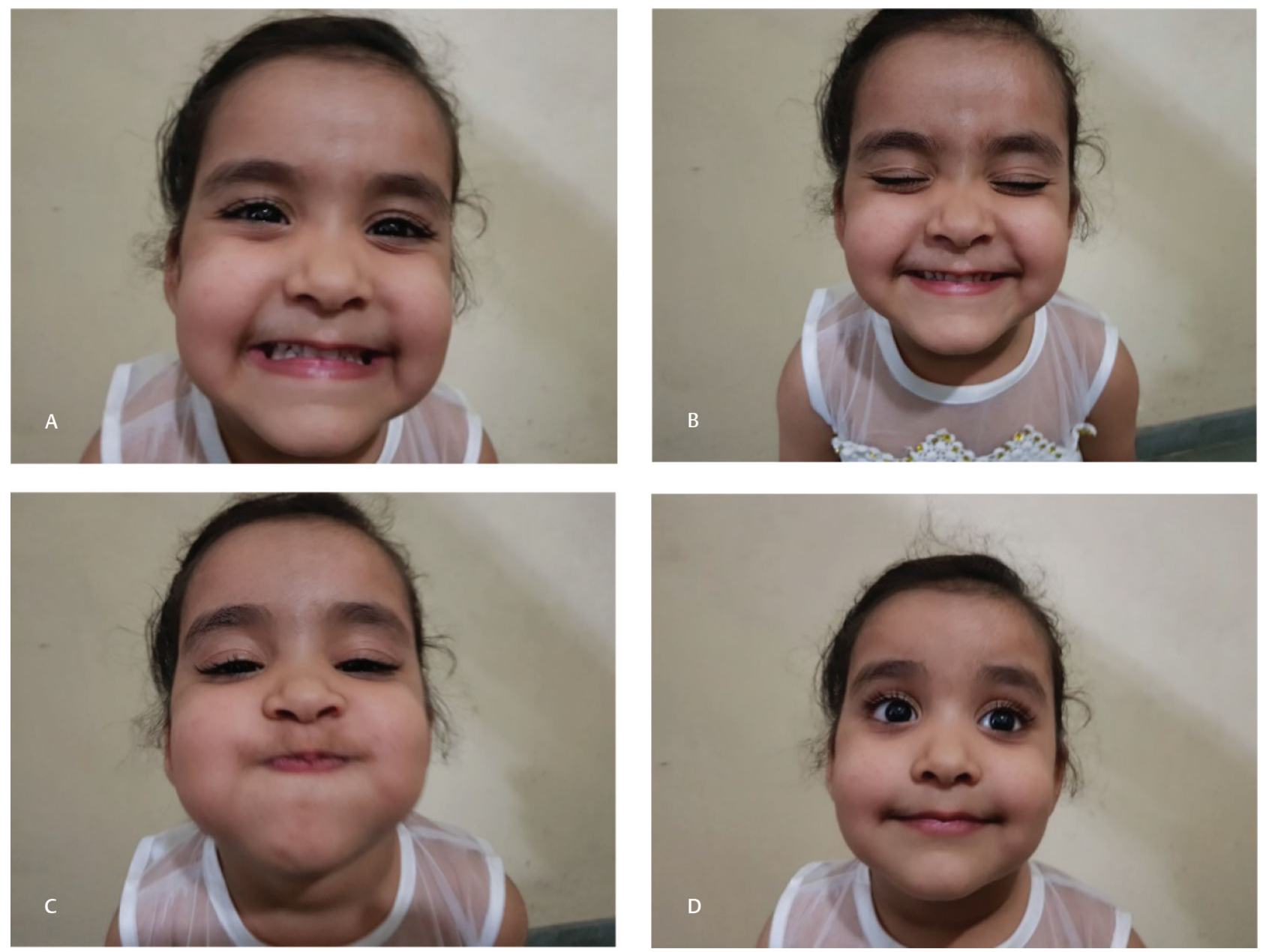

Fig. 6 (A-D) At visit after 8 weeks of treatment, the patient showed bilateral ability to (A) show teeth, (B) complete eye closure, (C) ability to puff air in the cheeks and (D) frown, bilateral grade I (normal) facial palsy.

\section{Video 1}

Patient at first visit. Online content including video sequences viewable at: https://www.thieme-connect.com/products/ ejournals/10.1055/s-0040-1708798.

\section{Video 2}

Patient at second visit, 2 weeks of commencing treatment. Online content including video sequences viewable at: https:// www.thieme-connect.com/products/ejournals/10.1055/ s-0040-1708798.

\section{Video 3}

Patient at third visit, 8 weeks of commencing treatment. Online content including video sequences viewable at: https://www.thieme-connect.com/ products/ejournals/10.1 055/s-0040-1708798.

be suffering from Bell's palsy. As she responded very well to steroids and antivirals, it further established the diagnosis of Bell's palsy.

\section{Conclusion}

Bilateral facial palsy is a condition with severe implications, especially when seen in children. Due to its functional and 
Table 1 Differential diagnosis of bilateral facial palsy

\begin{tabular}{|l|l|}
\hline Infections & Lyme disease \\
& Infectious mononucleosis \\
& Syphilis \\
& Meningitis \\
& Brain stem encephalitis \\
& Otitis media/cholesteatoma \\
& HIV \\
& HTLV-1 \\
& Post influenza \\
\hline Trauma & Skull fractures \\
& Mastoid surgery \\
& Parotid surgery \\
\hline Neurological & Guillain-Barre syndrome \\
& Pseudobulbar and bulbar palsy \\
& Multiple idiopathic cranial neuropathies \\
& Benign intracranial hypertension \\
& Melkersson-Rosenthal syndrome \\
\hline Neoplastic & Acute leukemia \\
& Bilateral acoustic neuroma \\
& Intrapontine and prepontine tumors \\
\hline Metabolic & Diabetes \\
& Acute porphyria \\
\hline Autoimmune & Sarcoidosis \\
& Amyloidosis \\
Vasculitis \\
\hline Idiopathic & Bell's palsy \\
\hline
\end{tabular}

Abbreviations: HIV, human immunodeficiency virus; HTLV, human T-cell leukemia virus.

aesthetic outcomes, it is a major concern for the parents. Various etiologies have been proposed for the bilateral palsy. A thorough evaluation leading to appropriate differential diagnosis and an early treatment is important. Along with this, parents must be reassured and counseled regularly.

\section{Conflict of Interest}

None declared.

\section{References}

1 Shargorodsky J, Lin HW, Gopen Q. Facial nerve palsy in the pediatric population. Clin Pediatr (Phila) 2010;49(5):411-417

2 Pothiawala S, Lateef F. Bilateral facial nerve palsy: a diagnostic dilemma. Case Rep Emerg Med 2012;2012:458371

3 Jain V, Deshmukh A, Gollomp S. Bilateral facial paralysis: case presentation and discussion of differential diagnosis. J Gen Intern Med 2006;21(7):C7-C10

4 Gleeson M, ed. Scott-Brown's Otorhinolaryngology, Head and Neck Surgery. 7th ed. Boca Raton, FL: CRC Press; 2013

5 Adour KK, Byl FM, Hilsinger RL Jr., Kahn ZM, Sheldon MI. The true nature of Bell's palsy: analysis of 1,000 consecutive patients. Laryngoscope 1978;88(5):787-801

6 Charles SB. The Nervous System of the Human Body. London, Longman, Rees, Orme, Brown and Green; 1830

7 Hammond WA. A Treatise on Diseases of the Nervous System. 8th ed. New York, NY : D. Appleton and company; 1890

8 Keane JR. Bilateral seventh nerve palsy: analysis of 43 cases and review of the literature. Neurology 1994;44(7):1198-1202

9 Teller DC, Murphy TP. Bilateral facial paralysis: a case presentation and literature review. J Otolaryngol 1992;21(1):44-47

10 Jairath V, Sehrawat M, Jindal N, Jain VK, Aggarwal P. Lyme disease in Haryana, India. Indian J Dermatol Venereol Leprol 2014;80(4):320-323

11 Khaw K, Rose G. Lyme disease facial palsy: differentiation from Bell's palsy Cholesterol screening programmes: how much potential benefit? BMJ 1989;299(September):605-606

$12 \mathrm{Kim}$ JK, Oh SY, Sohn EH, Hong YH, Jun SM, Bae JS. When is facial diplegia regarded as a variant of Guillain-Barré syndrome? J Peripher Nerv Syst 2015;20(1):32-36

13 Terada K, Niizuma T, Kosaka Y, Inoue M, Ogita S, Kataoka N. Bilateral facial nerve palsy associated with Epstein-Barr virus infection with a review of the literature. Scand J Infect Dis 2004;36(1):75-77

14 Benecke JE Jr. Facial paralysis. Otolaryngol Clin North Am 2002;35(2):357-365

15 May M. Disorders of viral origin. In: May M, Shaitkin BM, eds. The Facial Nerve. New York, NY: Thieme; 1986:365-399 